\title{
Accidental Entry of Foreign Body in Maxillary Sinus-A Case Report
}

\author{
Nishant Kumar*, Himanshu Bhutani, Pushpak Jain, Abhishek Verma, Sps Tomar, \\ Shaibal Chaterjee, Ankur Garg, Rohit Awana \\ Department of Oral and Maxillofacial Surgery, ITS Dental College, Hospital and Research Centre, Greater Noida, \\ India \\ Email: ${ }^{*}$ nishantkumarr@its.edu.in
}

Received 19 October 2014; revised 13 December 2014; accepted 7 January 2015

Copyright (C) 2015 by authors and Scientific Research Publishing Inc.

This work is licensed under the Creative Commons Attribution International License (CC BY). http://creativecommons.org/licenses/by/4.0/

c) (i) Open Access

\begin{abstract}
Extraction of the first molar or premolar is the commonest cause of oro-antral fistula. Management involves identification of the same, removal of any foreign body from the maxillary sinus, if present, followed by appropriate flap for closer. A case is presented when a gutta percha (GP) point was accidentally dislodged into the right maxillary sinus during preliminary diagnosis of the oro-antral fistula. The surgical management of the case is described and is the appropriate treatment plan.
\end{abstract}

Keywords

Gutta Percha, Maxillary Sinus, Caldwell-Luc Approach, Buccal Pad of Fat

\section{Introduction}

The oro-antral communication is a well-documented postoperative complication associated with the extraction of maxillary molar and premolar teeth. Foreign bodies can get into the maxillary sinus mainly due to trauma and accidents during dental or surgical treatment (iatrogenic). The reason why most foreign bodies lodge into the maxillary sinus at the dental office is because the bone of the maxillary sinus floor is very thin and in some persons the roots of the molars project through this bone. The scientific literature reveals that among the foreign bodies found in the maxillary sinus are dental burs, roots of teeth, amalgam, titanium implants, glass, impression dental materials and, bullets and gutta-percha points. Less found bodies include stones, matchsticks, wood and many others. We report a case of accidental entry of gutta percha point in maxillary sinus that was retrieved through Caldwell-Luc approach and incision was done by buccal fat of pad. The approach is also used for retrieval of maxillary teeth roots which get displaced in sinus and for management of maxillary sinusitis.

\footnotetext{
"Corresponding author.
}

How to cite this paper: Kumar, N., Bhutani, H., Jain, P., Verma, A., Tomar, S., Chaterjee, S., Garg, A. and Awana, R. (2015) Accidental Entry of Foreign Body in Maxillary Sinus-A Case Report. Open Journal of Stomatology, 5, 1-5. 


\section{Case Report}

A 30 years old female with history of nasal discharge following extraction of upper right molar was referred to department oral and maxillofacial surgery following the iatrogenic dislodgement of gutta percha (GP) point into the right maxillary sinus. The gutta percha point got dislodged into sinus during preliminary investigations.

Periapical and panoramic radiograph confirmed the presence of GP point in the right maxillary sinus (Figure 1). Treatment was planned to retrieve the gutta percha point by Caldwell-Luc approach and closure of oroantral communication using buccal fat pad. The GP point were visualized and removed, the maxillary sinus irrigated and the wound was sutured with 3-0 vicryl.

\section{Surgical Technique}

Right maxillary sinus was approached through the canine fossa by using the Caldwell-Luc approach, the procedure was performed under local anesthesia where an incision was made in the buccal sulcus from the lateral incisor to the first molar.

An elliptical incision was made in the right upper molar region, the epithelial tract with inflammatory tissue was completely excised, and two divergent incisions were extended into the vestibule. The trapezoidal buccal mucoperiostal flap was reflected from the alveolus and the lateral wall of the maxilla a window was made in lateral wall of maxillary sinus, the sinus lining was gently elevated till the GP was visible (Figure 2). The buccal fat pad was exposed through a $1 \mathrm{~cm}$ vertical incision through the periosteum posterior to the zygomatic buttres (Figure 3). The fat pad was gently advanced over the bony defect, and secured with sutures (Figure 4) after removing the gutta percha point (Figure 5). The mucoperiostal flap was replaced in its original position and sutured. After 10 days follow up, the surgical site was completely healed with no complications (Figure 6).

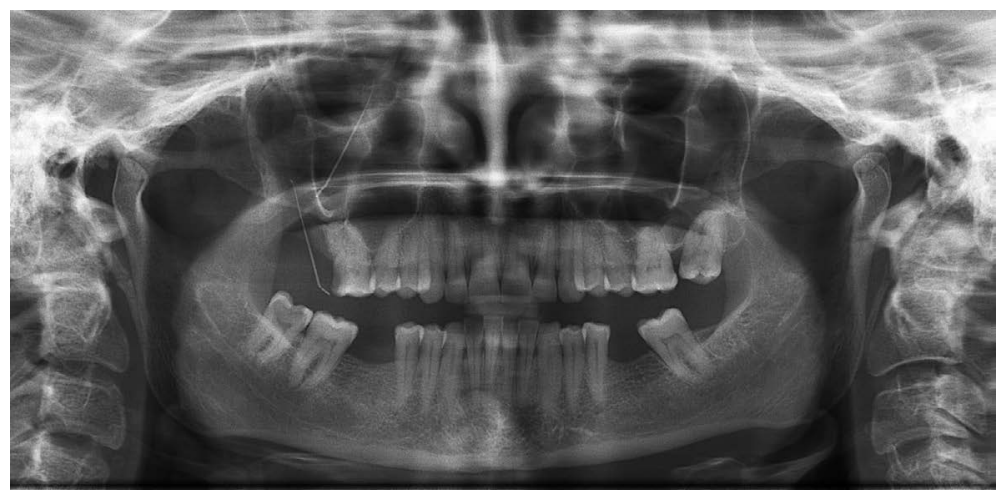

Figure 1. Orthopantomogram showing foreign body (gutta percha point) in the right maxillary antrum.

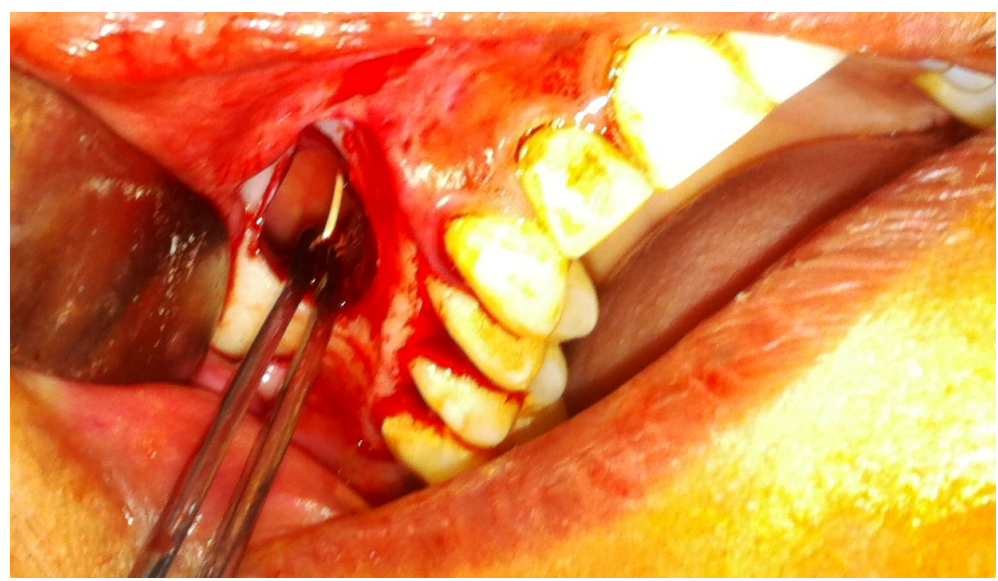

Figure 2. Gutta percha clearly visible in the right maxillary sinus through the Caldwell-Luc approach. 


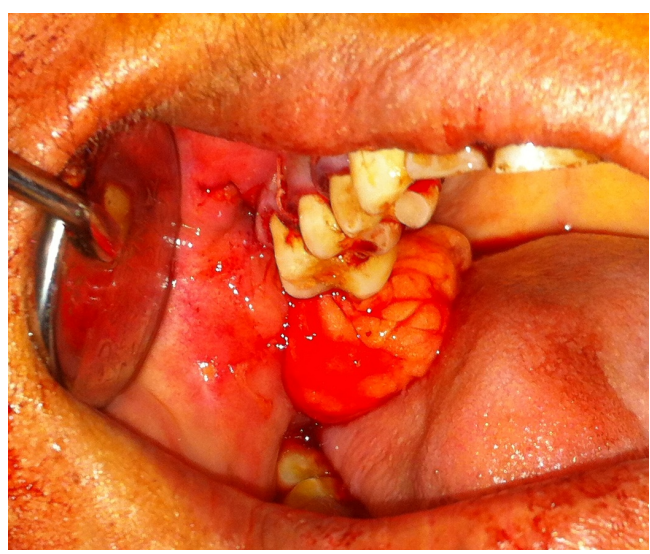

Figure 3. Buccal fat pad in right posterior region.

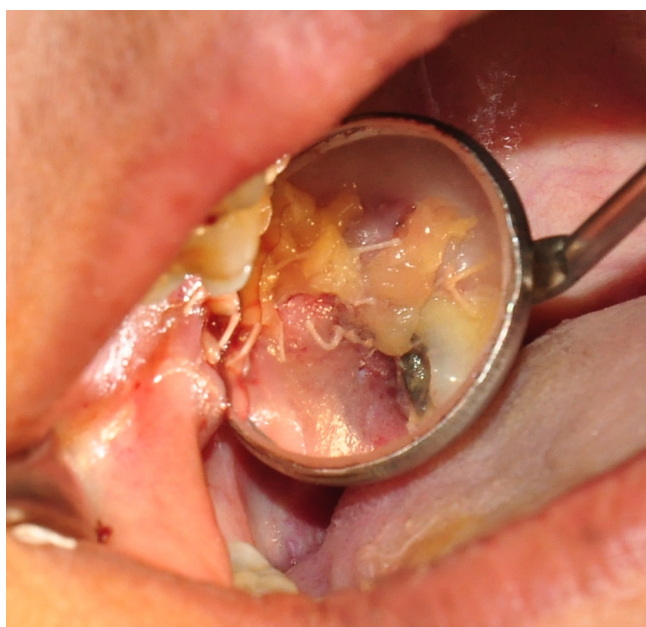

Figure 4. Closure of oroantral fistula by buccal fat pad.

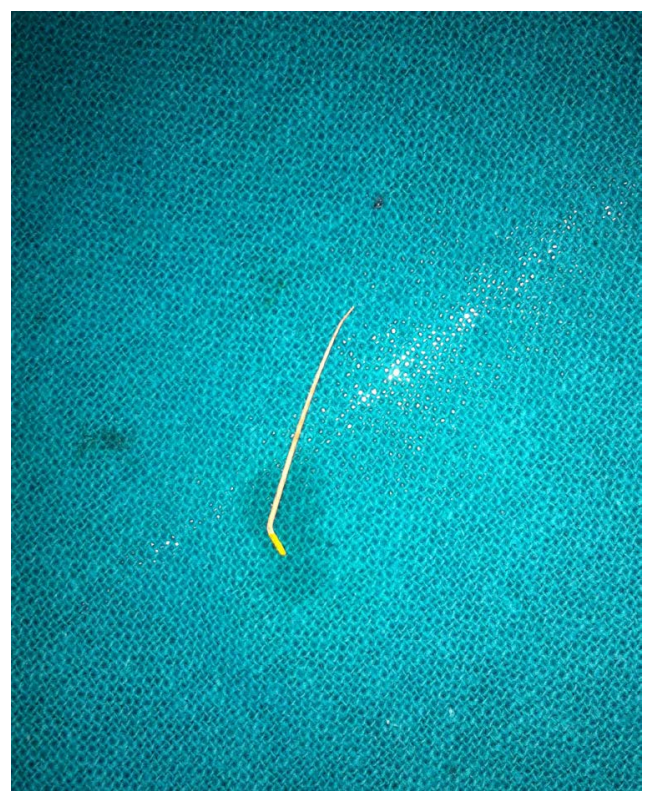

Figure 5. Gutta percha point retrieved. 


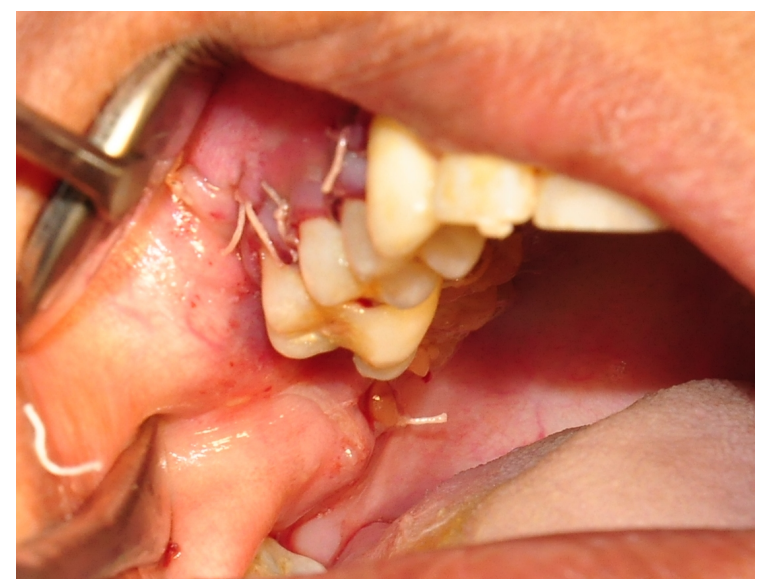

Figure 6. Follow up of the case after 10 days.

\section{Discussion}

The treatment modalities to repair the oroantral fistula/communication include local or free soft tissue flaps, with or without autogenous grafts or alloplastic implants. The closure of an oro-antral communication can be achieved by different techniques. Particular emphasis should be made in choosing the most appropriate method. We suggest the buccal flap for small and mesial fistulas, taking into consideration that additional surgery to reestablish the proper vestibular depth may be necessary. The palatal flap was found to be a feasible option for repairing oro-antral communication particularly for defects in the premolar area. The technique is simple and familiar to the oral and maxillofacial surgeon. This procedure is highly recommended when an optimal length/ width flap can be maintained.

The use of the buccal fat pad in the closure of OAF was first reported by Egyedi [1]. Since then, it has been referred in the literature by different names. Scammon [2] was the first to describe the anatomy of the BFP, followed by Goughran. Anatomically the buccal fat pad is described consisting of a central body and 4 extensions. The blood supply of the buccal fat pad comes from 3 sources: the maxillary artery (buccal and deep temporal branches), the superficial temporal artery (transverse facial branch), and the facial artery.

The buccal pad flap has been used for a variety of purposes, owing to its physical and biological properties, and the results have encouraged clinicians to make use of its potential benefits. The most common use of the buccal pad flap has been in the closure of big posterior oroantral communications, followed by post excision reconstruction. The rich blood supply may explain the high success rate. It also may be one reason for the quick epithelialization of the fat. Fujimura [3] et al. showed that BFP started to epithelialize in a week and completed its epithelialization within 6 weeks. Most authors agreed on the surgical technique to expose the BFP, similar to the one we performed. The alternative ways to close an oroantral communication includes laser bio-stimulation (over 5 days), transplantation of a mature third molar (followed by RCT of the tooth 5 - 6 weeks later), autogenous monocortical bone blocks (from the chin). Stajcis [4] advocated the use of the buccal fat pad for OAF closure without any complications, and we found that BFP was very useful for OAF closure without any disturbance and scaring in the vestibule of OAF closure such as buccal advancement flap.

The most commonly found foreign bodies are the displaced fractured roots of teeth and in some instances displaced whole teeth [5]. Other foreign bodies include dental burs [6], dental implants [7], GP points and silver points [8]. More bizarre foreign bodies include: bullets [9], pieces of glass, stones [10], wood [11], grasses, match sticks [12] and sand [13]. Killey and Kay [14] noted that although sinusitis was a common occurrence after entry of a foreign body into the antrum, the onset of change in the antral lining may be delayed for months or even years. Of the paranasal sinuses, the maxillary antrum is the most commonly affected, usually secondarily to the common cold [15]. The rapid epithelialization of the uncovered fat is a peculiar feature of the BFP flap stalk and has been confirmed by histopathological studies [16]. The fat pad provides a good rate of epithelialization and a low rate of failure [17] [18].

\section{Conclusions}

A Caldwell-Luc operation is advised in order to remove and examine disease located in the maxillary sinus. 
Since it was first performed early in this century, a vast amount of knowledge exists, not only about its proven value as a method to treat maxillary sinus disease, but also about the potential risks, which, fortunately, are infrequent.

The easy mobilization of the buccal fat pad, its excellent blood supply, and minimal donor site morbidity make it an ideal flap for OAF closure. We believe that the BFP should be used more often for this clinical application.

\section{References}

[1] Egyedi, P. (1977) Utilization of the Buccal Fat Pad for Closure of Oroantral and/or Oronasal Communication. Journal of Maxillofacial Surgery, 5, 241-247. http://dx.doi.org/10.1016/S0301-0503(77)80117-3

[2] Baumann, A. (2000) Application of the Buccal Fat Pad in Oral Reconstruction. Oral and Maxillofacial Surgery, 58, 163-166.

[3] Fujimura, N. and Nagura, H. (1990) Grafting of the Buccal Fat Pad into Palatal Defect. Journal of Cranio-MaxilloFacial Surgery, 18, 219-223. http://dx.doi.org/10.1016/S1010-5182(05)80415-9

[4] Stajcis, Z. (1992) The Buccal Fat Pad in the Closure of Oroantral Communication. Journal of Cranio-Maxillo-Facial Surgery, 20, 193-198. http://dx.doi.org/10.1016/S1010-5182(05)80314-2

[5] Worth, H.M. (1972) Principles and Practice of Oral Radiologic Interpretation. Year Book Medical Publishers Inc., Chicago, 207-212.

[6] Abe, K., Beppu, K., Shinohara, M. and Oka, M. (1992) An Iatrogenic Foreign Body (Dental Bur) in the Maxillary Antrum: A Report of Two Cases. British Dental Journal, 173, 63-65. http://dx.doi.org/10.1038/sj.bdj.4807941

[7] Iida, S., Tanaka, N., Kogo, M. and Matsuya, T. (2000) Migration of a Dental Implant into the Maxillary Sinus. A Case Report. International Journal of Oral and Maxillofacial Surgery, 29, 358-359. http://dx.doi.org/10.1016/S0901-5027(00)80052-1

[8] Minkow, B., Laufer, D. and Gutman, D. (1977) Acute Maxillary Sinusitis Caused by a Gutta Percha Point. Refuat Hapeh Vehashinayim, 26, 33-34.

[9] Kozlowski, K. (1965) Metallic Foreign Body in the Maxillary Sinus. Lancet, 7361, 698.

[10] Makino, H. (1955) A Case of Foreign Body of Maxillary Sinus Which Occurred from Traumatic Injury. J Otolaryngol Jpn, 30, 142-145.

[11] Tada, E., Sato, S., Hattori, M., Ogawa, K. and Ootani, I. (1967) A Foreign Body of the Maxillary Sinus with Facial Fistula. J Otolaryngol Jpn, 39, 35-39.

[12] Rahman, A. (1982) Foreign Bodies in the Maxillary Antrum. British Dental Journal, 153, 308. http://dx.doi.org/10.1038/sj.bdj.4804926

[13] Dunagan, D.P., Cox, J.E., Chang, M.C. and Haponik, E.F. (1997) Sand Aspiration with Near-Drowning. Radiographic and Bronchoscopic Findings. American Journal of Respiratory and Critical Care Medicine, 156, 292-295. http://dx.doi.org/10.1164/ajrccm.156.1.9610092

[14] Killey, H.C. and Kay, L.W. (1964) Possible Sequelae When a Tooth or Root Is Dislodged into the Maxillary Sinus. British Dental Journal, 116, 73.

[15] Haraji, A. and Zare, R. (2007) The Use of Buccal Fat Pad for Oro-Antral Communication Closure. J Mashhad Dent Sch Mashhad Univ Med Sci, 31, 9-11.

[16] Ferrari, S., Ferri, A., Bianchi, B., Copelli, C., Magri, A.S. and Sesenna, E. (2009) A Novel Technique for Cheek Mucosa Defect Reconstruction Using Apedicled Buccal Fat Pad and Buccinatormyomucosal Island Flap. Oral Oncology, 45, 59-62. http://dx.doi.org/10.1016/j.oraloncology.2008.03.018

[17] Liversedge, R.L. and Wong, K. (2002) Use of the Buccal Fat Pad in Maxillary and Sinus Grafting of the Severely Atrophic Maxilla Preparatory to Implant Reconstruction of the Partially or Completely Edentulous Patient: Technical Note. International Journal of Oral Maxillofacial Implants, 17, 424-428.

[18] Ferrari, S., Ferri, A., Bianchi, B., Copelli, C., Magri, A.S. and Sesenna, E. (2009) A Novel Technique for Cheek Mucosa Defect Reconstruction Using a Pedicledbuccal Fat Pad and Buccinatormyomucosal Island Flap. Oral Oncology, 45, 59-62. http://dx.doi.org/10.1016/j.oraloncology.2008.03.018 
Scientific Research Publishing (SCIRP) is one of the largest Open Access journal publishers. It is currently publishing more than 200 open access, online, peer-reviewed journals covering a wide range of academic disciplines. SCIRP serves the worldwide academic communities and contributes to the progress and application of science with its publication.

Other selected journals from SCIRP are listed as below. Submit your manuscript to us via either submit@scirp.org or Online Submission Portal.
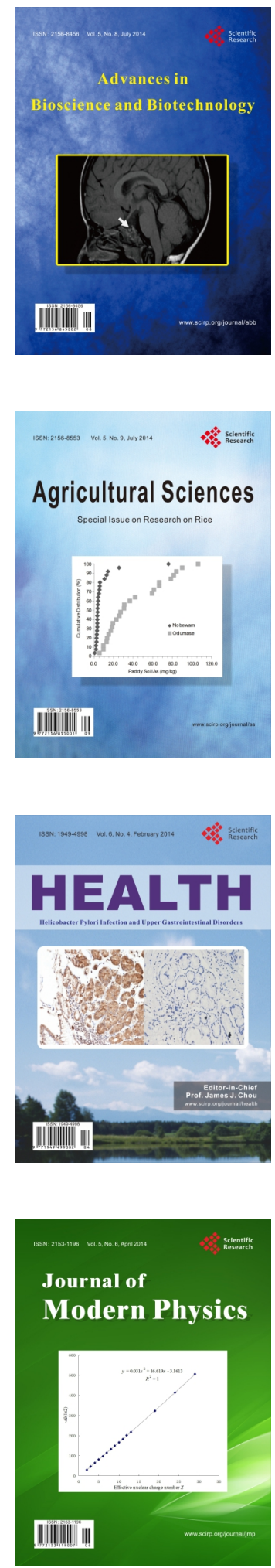
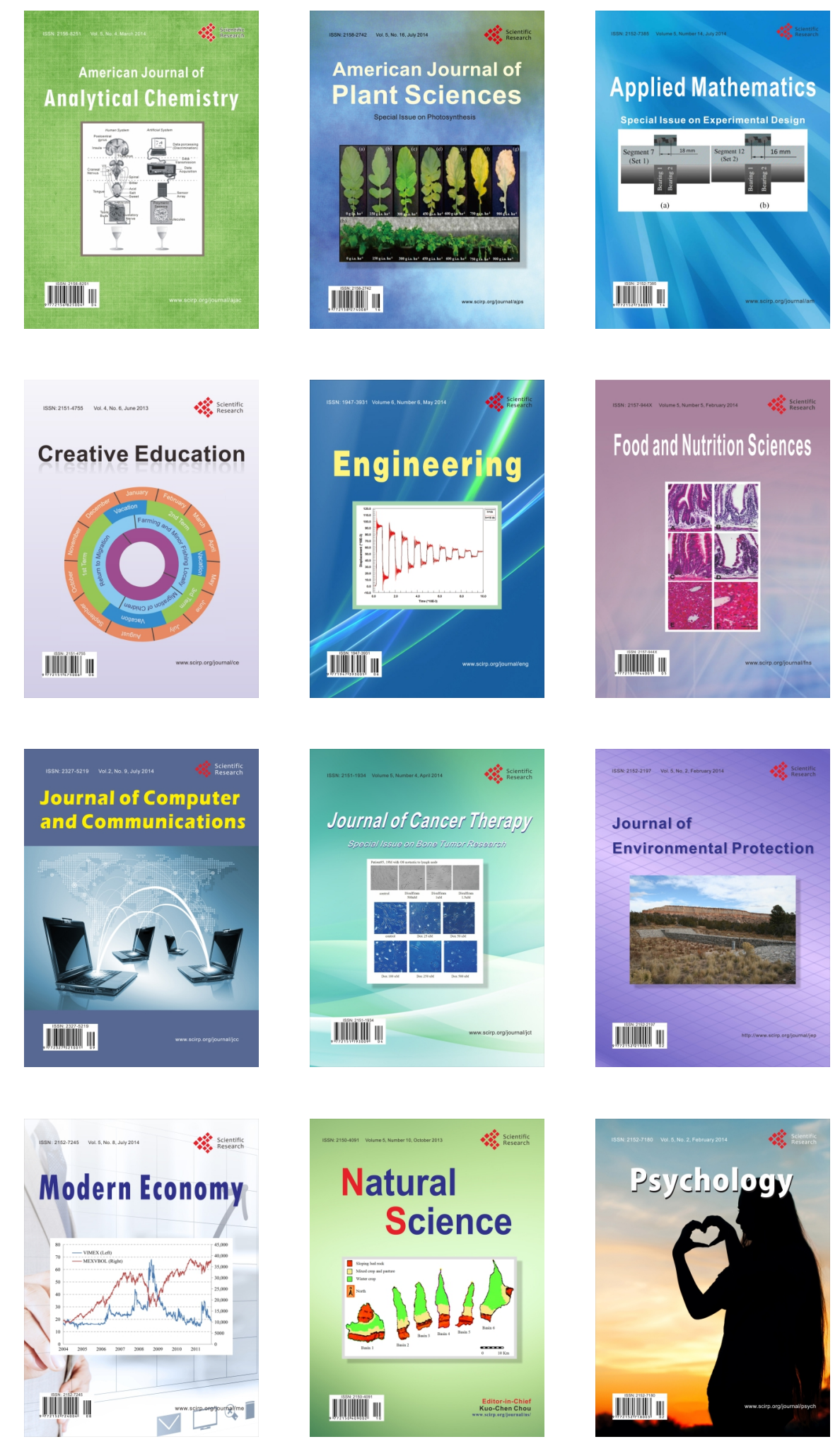